\title{
Extrapolating future Arctic ozone losses
}

\author{
B. M. Knudsen ${ }^{1}$, N. R. P. Harris ${ }^{2}$, S. B. Andersen ${ }^{1}$, B. Christiansen ${ }^{1}$, N. Larsen ${ }^{1}$, M. Rex ${ }^{3}$, and B. Naujokat ${ }^{4}$ \\ ${ }^{1}$ Danish Meteorological Institute, Copenhagen, Denmark \\ ${ }^{2}$ European Ozone Research Coordinating Unit, Cambridge, UK \\ ${ }^{3}$ Alfred Wegener Institute for Polar and Marine Research, Potsdam, Germany \\ ${ }^{4}$ Free University of Berlin, Berlin, Germany
}

Received: 3 May 2004 - Published in Atmos. Chem. Phys. Discuss.: 16 June 2004

Revised: 3 September 2004 - Accepted: 10 September 2004 - Published: 13 September 2004

\begin{abstract}
Future increases in the concentration of greenhouse gases and water vapour may cool the stratosphere further and increase the amount of polar stratospheric clouds (PSCs). Future Arctic PSC areas have been extrapolated from the highly significant trends 1958-2001. Using a tight correlation between PSC area and the total vortex ozone depletion and taking the decreasing amounts of ozone depleting substances into account we make empirical estimates of future ozone. The result is that Arctic ozone losses increase until 2010-2015 and decrease only slightly afterwards. However, for such a long extrapolation into the future caution is necessary. Tentatively taking the modelled decrease in the ozone trend in the future into account results in almost constant ozone depletions until 2020 and slight decreases afterwards. This approach is a complementary method of prediction to that based on the complex coupled chemistry-climate models (CCMs).
\end{abstract}

\section{Introduction}

The success of the Montreal Protocol and its amendments should lead to decreasing amounts of ozone depleting substances in the future. This in turn would lead to decreased ozone depletion if other factors remained unchanged. However, the stratosphere has been cooling for decades and some measurements suggest that the amount of water vapour in the stratosphere is increasing. Both these factors would tend to increase the ozone depletion in the Arctic vortex. Predicting the future ozone layer therefore involves a delicate balance between competing processes.

The tools used to predict future ozone depletion are chemistry-climate models. These CCMs, while physically based, parameterise many important processes affecting the

Correspondence to: B. M. Knudsen

(bk@dmi.dk) ozone layer, and do not include others. There is no agreement between models as to whether ozone will increase or decrease in the future. One of the reasons is that the current CCMs have difficulty in calculating correct polar temperatures, which are essential for determining the amount of ozone depletion. The range of model predictions of Arctic temperatures is currently too wide make reliable predictions of future Arctic ozone losses, even given the large interannual variability in the Arctic and the chaotic nature of the atmosphere (WMO, 2003).

CCMs also have difficulties in representing two other important processes for polar ozone loss: the increase in stratospheric water vapour and the formation mechanism for solid type PSCs. The observed increase in water vapour (Oltmans et al., 2000; Rosenlof et al., 2001) may have contributed substantially (Forster and Shine, 2002; Oinas et al., 2001) to the observed cooling in the stratosphere (Ramaswamy et al., 2001; WMO, 2003). Current CCMs include little more than that $\sim 1 / 3$ of the trend in water vapour, which is due to increasing methane (WMO, 2003). The lack of understanding of the formation of solid type PSCs (Tolbert and Toon, 2001) makes it difficult e.g. to model denitrification due to sedimentation of PSC particles, which can increase ozone depletion substantially (Waibel et al., 1999).

Although there might be some cancellation of errors in the CCM's we thus have limited confidence in the predictions of future Arctic ozone losses made with even the best present day CCMs. Therefore, we have developed a complementary approach based on the observed behaviour of the stratosphere over the past $40-50$ years. The idea is that if the atmosphere currently is too difficult to model we need to let nature to tell us what is going on. We base this approach on the tight correlation between PSCs and the total vortex ozone depletion observed by Rex et al. (2004). We do the extrapolation into the future using the highly significant increase in PSC occurrence (due to cooling in the Arctic vortex) from 1958 2001, taking into account the decreasing amounts of ozone 


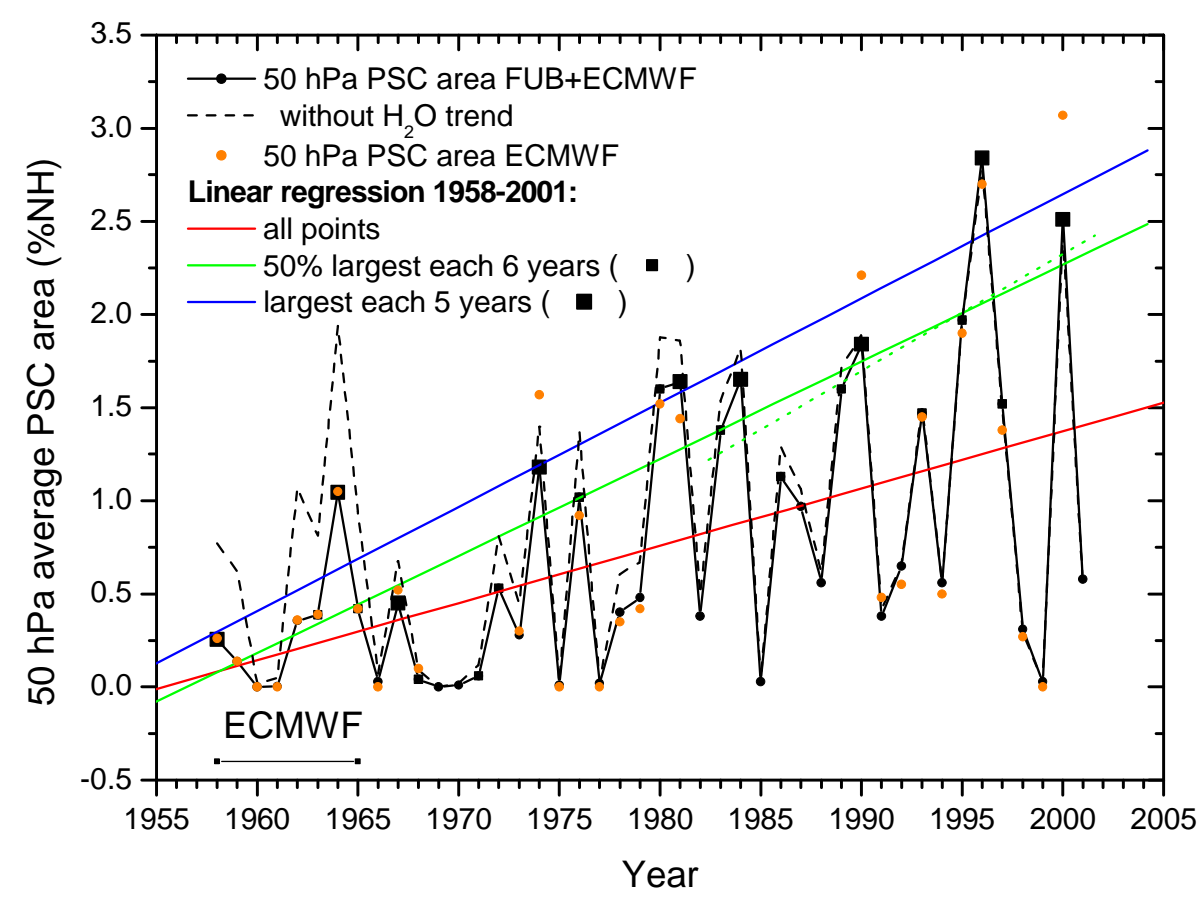

Fig. 1. Mid December to end of March mean NH $50 \mathrm{hPa}$ PSC areas based on FUB and ECMWF analyses with (solid) and without (dashed) incorporation of the observed $\mathrm{H}_{2} \mathrm{O}$ trend. Linear regression lines using all points (red), the $50 \%$ largest PSC areas in 6-year intervals (green) for 1958-2001 (solid) and 1984-2001 (dotted), and using the largest PSC areas in 5-year intervals (blue) are shown.

depleting substances in the future. In this simplistic approach the water vapour trend and denitrification is included implicitly. Although such simple extrapolations have large associated uncertainties, these may not be larger than the uncertainties connected to CCMs. These extrapolations thus represent a useful complementary prediction to present day CCMs.

\section{Data}

\subsection{Temperatures and calculation of PSC area}

The Free University of Berlin (FUB) has made historical wintertime analyses of the $\mathrm{NH}$ stratosphere, which primarily use radiosonde data, from July 1965 to June 2001 (Labitzke et al, 2002; Pawson and Naujokat, 1997). They are available in a $10^{\circ}$ latitude-longitude grid. Since 1977 a $5^{\circ}$ grid was used, but for consistency the data set was thinned to the $10^{\circ}$ grid.

The ECMWF 40 year reanalyses (ERA40) (Simmons and Gibson, 2000) covers the period 1957-2002. It uses a 3D variational analysis at T159 resolution and 60 levels in the vertical. The data were extracted in a $5^{\circ}$ lat-lon grid from T21 truncated fields. These data were then thinned to the $10^{\circ}$ FUB grid.

There are no long term observational records of PSCs suitable for this analysis. Accordingly the PSC area is defined here as the area where the temperature is below the nitric acid trihydrate condensation temperatures $\left(\mathrm{T}_{\mathrm{NAT}}\right)$ (Hanson and Mauersberger, 1988). The quality of the predicted temperatures below $\mathrm{T}_{\mathrm{NAT}}$ has been assessed by comparison of both the high-resolution ERA40 analyses and first guess fields (i.e. the 6-h forecasts from the last analysis, which is independent from individual radiosondes) to radiosondes. The extent of such low temperatures at $50 \mathrm{hPa}$ in ERA40 was 610 and 1-2\% lower than the radiosonde extent in 1995/1996 and 1996/1997 (Knudsen, 2003), respectively. The NH winter averaged PSC extent using FU-Berlin data is 11 and 5\% higher than the ERA40 PSC extent in 1995/1996 and 1996/1997, respectively. Thus, both the ERA40 and the FU-Berlin PSC extent agrees well with observations. The ERA15 reanalysis (Gibson et al., 1997), which has also been used, does not have a comparable accuracy of temperatures (Knudsen, 1996).

The FUB data are valid for 0:00 UT, whereas the ECMWF data are calculated for 12:00 UT. Tests show that this has only a minor effect on the PSC areas. The same is true for PSC areas calculated at higher resolution (up to a $2.5^{\circ}$ lat-lon grid), due to the long averaging period.

Changes in the observation system influence the quality of the meteorological analyses. In 1957, the International Geophysical Year, the number of radiosondes became comparable to the current number. In 1964 the former Soviet Union started supplying radiosonde data above $100 \mathrm{hPa}$ and in 1979 satellite data became available. However, the averaged PSC area over the whole winter is a relative robust 
quantity, which does not depend on small errors. The FUBerlin analyses have remained almost unchanged during the period and should thus be well suited for trend studies.

\subsection{Water vapour}

Following Forster and Shine (2002), we have adopted a homogeneous $\mathrm{H}_{2} \mathrm{O}$ trend of 0.05 ppmv/year. This trend is derived for midlatitudes and may not be directly transferable to the Arctic. The reference point is the UARS 1992-1998 HALOE+MLS climatology for February (http://code916.gsfc.nasa.gov/Public/Analysis/ UARS/urap/home.html) at $70^{\circ} \mathrm{N}$ equivalent latitude. With this trend the $50 \mathrm{hPa} \mathrm{H}_{2} \mathrm{O}$ mixing ratios $\left(\mathrm{T}_{\mathrm{NAT}}\right.$ ) are $4.40 \mathrm{ppmv}(195.0 \mathrm{~K})$ in $1995,3.65 \mathrm{ppmv}(194.3 \mathrm{~K})$ in 1980 , $2.85 \mathrm{ppmv}(193.2 \mathrm{~K})$ in 1964 and $2.55 \mathrm{ppmv}(192.8 \mathrm{~K})$ in 1958. The nitric acid mixing ratio used is the LIMS January value at $76^{\circ} \mathrm{N}$ of $9 \mathrm{ppbv}$. In the SH the $70 \mathrm{hPa} 64^{\circ} \mathrm{S}$ value of $6 \mathrm{ppbv}$ was chosen in May, before denitrification and dehydration sets in. The $\mathrm{SH} \mathrm{H}_{2} \mathrm{O}$ mixing ratio in May at $70 \mathrm{hPa}$ and $70^{\circ} \mathrm{S}$ is also $4.4 \mathrm{ppmv}$.

\section{$3 \quad$ PSC trends}

Figure 1 shows the mid December to end of March mean $50 \mathrm{hPa}$ PSC area for FUB and ERA-40 analyses. The FUB and ERA40 data agree quite well in most years. One exception is in 2000, where large temperature biases occurred over the poles in the ERA40 data (Knudsen, 2003). When this figure was prepared the ERA40 reanalyses had not yet been completed. We have therefore used a combined data set with ERA40 data 1958-1965 and FUB data afterwards (solid line).

In the absence of a trend in $\mathrm{H}_{2} \mathrm{O}, \mathrm{T}_{\mathrm{NAT}}$ would be constant and the PSC areas would follow the dashed black line. The linear regression line though all points on the black line, which are independent, is the solid red line. The PSC areas increase with more than $99.9 \%$ confidence $(4 \sigma)$ during the period (von Storch and Zwiers, 1998, Sect. 8.3.7). Without the trend in $\mathrm{T}_{\mathrm{NAT}}$ the PSC increase would still be significant with more than $98 \%$ confidence.

The Arctic winter stratosphere is sometimes disrupted by major stratospheric warmings, which usually bring an end to the PSC season and limit the ozone loss. The largest ozone losses occur in the cold uninterrupted winters. To examine this group of winters separately, the maximum PSC areas in successive 5-year intervals (2001-1997, 1996-1992, etc.) are extracted (large squares)(Rex et al., 2004). The first interval (1958-1961) is only 4 years long. Linear regression reveals a highly significant (more than $99.99 \%$ confidence $(8 \sigma))$ upward trend in these 9 maximum PSC areas. Such PSC areas are expected statistically only every fifth winter, so we have also examined the trends of the largest half of the PSC areas in 6-year intervals (squares; 2001-1996, 1995-
1990, etc.) which are expected statistically every second winter. These trends are the main focus of this paper.

The first interval (1958-1959) is only 2 years long, and the larger of these two PSC areas is included in the trend calculations. In fact it would also have been chosen in the 6-year interval from 1958-1963. Again highly significant upward trends are obtained $(8 \sigma)$. Sensitivity studies reveal that going to 8-year intervals or starting the intervals in 1958 (both for 6 and 8 year intervals) changes the calculated trend by a factor ranging from 0.95-1.04. Going to 4-year intervals changes the calculated trend by a factor of 0.85 and decreases the significance of the trend substantially. This is due to inclusion of the small PSC area in 2001.

The calculation have been performed until 2001 because that is the end of the FU-Berlin record. Updating the trends to 2004 would result in smaller PSC trends. However, there have been major mid-winter warmings in 5 out of the last 6 Arctic winters, compared to a long-term average of 1 in 2 winters, and so there is a risk of introducing a bias in the analysis. To give some idea of the magnitude of this effect, the data record was extended using ECWMF operational data for 2002-2004. Then the trends for all, the 50\% largest, and the maximum PSC areas would reduce by 29,33 , and $4 \%$ of the original trends, respectively. The trends would still be highly significant. Going to the other extreme of ending the trends in 1997 after 6 winters in row without major warmings would increase the trend for all PSC areas by $26 \%$.

Since 1984 the FUB data over data-sparse regions have been supplemented by satellite derived data. We have therefore calculated the trends of the 50\% largest PSC areas for the period 1984-2001. The slope is $0.063 \pm 0.032 \% \mathrm{NH} /$ year $(1 \sigma)$ and is significant at the $90 \%$ confidence limit, when the small numbers of data points are taken into account (von Storch and Zwiers, 1998, Sect. 8.3.7). As seen in the figure the 1984-2001 trend is close to the trend over the whole period.

\section{Correlation between PSC area and ozone depletion}

Vortex averaged ozone depletions in the Arctic from 400$550 \mathrm{~K}$ potential temperature have been calculated by Rex et al. (2004) from 1992-2000 and also in 2003, and they form probably the most accurate and consistent data set for Arctic vortex ozone depletions. Although there are certain assumptions involved in this method, it does give a correct depletion in the winter 1999/2000 (Lait et al., 2002; Schoeberl et al., 2002). It has been shown that mixing ideally should be taken into account at the bottom of the vortex and below (Knudsen et al., 1998) and in some years even above (Grooß and Müller, 2002).

Rex et al. (2004) found a high correlation between mean PSC volume and mean end-of-winter column ozone depletion. To be able to use the FUB data we here use $50 \mathrm{hPa}$ PSC areas instead, and to compare with the Antarctic ozone 


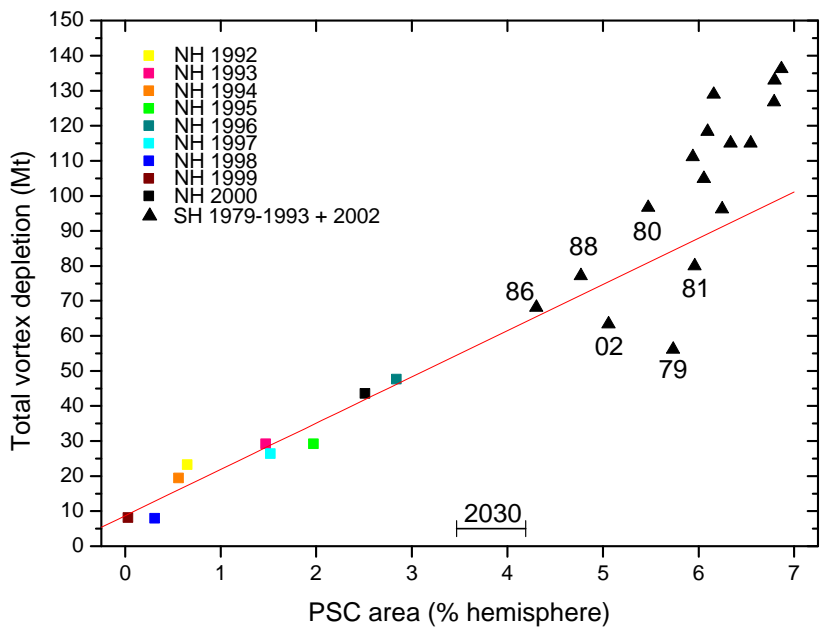

Fig. 2. Total NH vortex ozone depletions $1992-2000$ as a function of average PSC areas (squares) and the corresponding regression line (red). SH results are shown with triangles and the year is given for the warmest winters.

hole the total vortex depletion in Mt is used instead of the column depletion. Another advantage of using the total vortex depletion in $\mathrm{Mt}$ is that this quantity determines how large an influence the vortex depletion has on ozone levels at midlatitudes after break-up of the vortex (Knudsen and Grooß, 2000; Knudsen and Andersen, 2001). The edge of the vortex used to calculate the vortex area is the position of largest gradient in $475 \mathrm{~K} \mathrm{PV}$. The vortex area was averaged in the period mid December to end of March, in which the PSC areas were calculated. In 1997 and 1999 the vortex did not establish at $475 \mathrm{~K}$ before around 8 January, so the vortex areas are calculated as of this date.

Figure 2 shows the remarkably good correlation (correlation coefficient 0.96 ) of the total depletion with the PSC area for the period 1992-2000 for the NH. Also shown are the $68 \%$ confidence limits on the $50 \%$ largest PSC areas for 2030. One question is whether this correlation can be extended to these larger PSC areas expected in a future colder stratosphere, as it is possible that we have reached some kind of saturation where larger PSC areas do not lead to larger ozone losses. To investigate this we turn to the $\mathrm{SH}$, where larger PSC areas do occur. The SH temperatures are taken from the ERA-15 reanalyses from 1979-1993. Earlier years have not been used because the lack of satellite data is a serious problem for SH analyses (A. Simmons, personal communication). Later years have been omitted because then ERA15 data would not be available and adding more points in the upper right corner of the plot would not be of any help. The only exception is the year 2002, which was unusually warm with PSC areas close to the NH values.

Possibly the best available estimate of the long-term ozone vortex depletion in the $\mathrm{SH}$ is the October mean column ozone from Halley $\left(76^{\circ} \mathrm{S}, 26^{\circ} \mathrm{W}\right)$ (WMO, 1995, updated courtesy

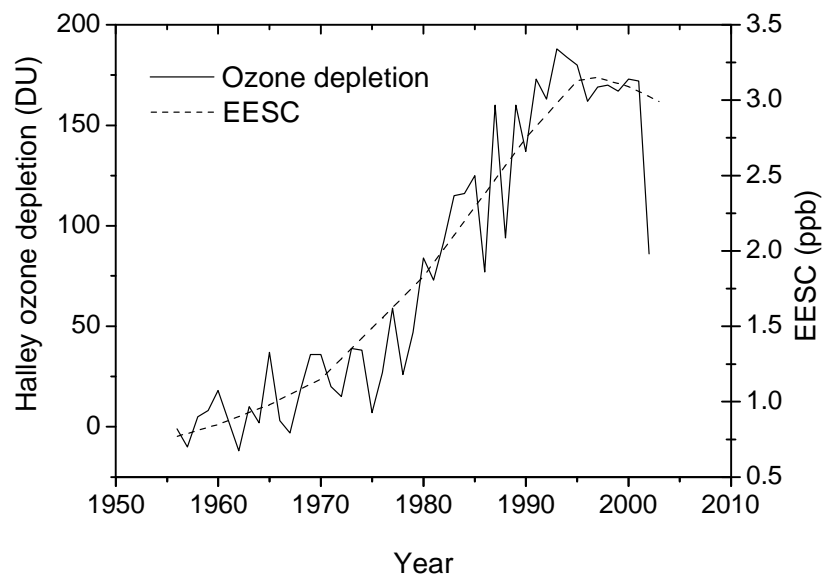

Fig. 3. Development of the column ozone depletion inferred from Halley data and the EESC.

J. D. Shanklin) minus the 1956-1959 mean (310 DU). The column ozone at Halley is of course lower than in the vortex mean, but so is the climatological mean at Halley.

Model calculations (Sinnhuber et al., 2002) show that the ozone loss is proportional to the equivalent effective stratospheric chlorine (EESC) loading, which incorporates bromine. Figure 3 shows that this is a fair assumption for the Antarctic ozone losses. In order to compare to the current $\mathrm{NH}$ depletions we have scaled the $\mathrm{SH}$ depletions up to the 1992-2000 halogen loading. This is done by dividing the SH depletions by the fraction of EESC in each year relative to the 1992-2000 average. The period during which the average PSC area is calculated is mid July to end of October. This is one month later in the season than in the $\mathrm{NH}$ because the $\mathrm{SH}$ vortex is much more pole-centred and sunlight reaches Halley later than it reaches the NH vortex. In the SH the PSC areas before mid July would not add to the ozone depletion since dehydration and denitrification would occur anyway. The level used is $70 \mathrm{hPa}$ because the ozone depletion in the SH vortex occurs lower than in the NH. The vortex area used is $12.5 \%$ of the $\mathrm{SH}\left(61^{\circ} \mathrm{S}\right.$ equivalent latitude) taken from the $550 \mathrm{~K} 1979-2000$ mean (WMO, 2003). Figure 2 justifies the assumption that further increases in the $\mathrm{NH}$ winter averaged PSC areas would lead to further ozone loss.

\section{Future ozone losses}

The linear regression lines in Fig. 1 have been extended to 2030, giving our best estimate of the future PSC areas. By combining these with the correlation between PSC area and ozone depletion from Fig. 2 and scaling the results by the fraction of EESC relative to the 1992-2000 average (WMO, 2003) to allow for decreasing EESC we obtain the future 
predictions of the ozone losses in Fig. 4. The dashed lines give $68 \%$ confidence intervals for the means at each year (Von Storch and Zwiers, 1998, Sect. 8.3.10) taking only the uncertainties in the PSC area regressions into account (note that this does not mean that $68 \%$ of the depletions will lie within the dashed lines, because individual depletions have a larger variation than the mean). Almost the same confidence intervals for the future parts of the lines are obtained by using lines crossing the regression line at the central year (1979.5) in Fig. 2 with the slope of the regression line \pm the standard deviation of the slope. To get $95 \%$ confidence limits the line spacing would have to be approximately doubled. Due to the small number of points, the line spacing for the maximum PSC area in 5-year intervals would, however, increase by a factor of 2.14 instead of 2 .

The largest PSC areas in 5-year intervals lead to the largest ozone depletion in the future, but such depletion is only expected statistically every 5 th year. Generally, we predict that the ozone depletion will increase, reach a maximum between 2010 and 2015, and then decrease slightly before 2030. For comparison, the CCMs do not agree on whether or not ozone depletion will increase in the future and show a substantial recovery by 2030 (Austin et al., 2003; WMO, 2003). It should be noted that by 2030 uncertainties are quite large in any prediction and in particular in our extrapolation.

While the ozone depletion in the Arctic vortex might match the amount of ozone depletion in the $\mathrm{SH}$ in the warmest years of the 1980s (without the scaling to the 19922000 mean EESC), there is no indication that it will ever reach current levels of total depletion (in Mt) in the Antarctic ozone hole. The Antarctic column depletions (in DU) during the warmest years in the 1980's were already surpassed in the Arctic in 1996.

We have performed a sensitivity study of what could influence the future predictions for the case with the $50 \%$ largest PSC areas. As shown in Fig. 5, using only the FUB data (black line) would increase the predicted ozone loss. The reasons why this might give a better prediction are a better consistency of the data and the fact that former Soviet Union radiosonde temperatures above $100 \mathrm{hPa}$ are only available since 1964. Further, radiosondes might have had difficulties in observing very low temperatures in the early years (Pawson and Naujokat, 1997). However, the FUB period may be biased by 5 out of the first 6 years being warm. It is informative to calculate how often such an event occurs. If the chance of a "warm" winter is $\frac{1}{2}$, the chance of at least 5 out of 6 winters being warm is $7 \times\left(\frac{1}{2}\right)^{6}=0.11$. Such an event is therefore expected every 55 years.

The $\mathrm{H}_{2} \mathrm{O}$ trend is not fully explained. Scaife et al. (2003) showed that part of the trend is due to the upward trend in the Southern Oscillation Index (SOI). According to Boer et al. (2004) the change in the SOI may be due to increased well-mixed greenhouse gases (WMGHG) and may thus continue in the future. On the other hand Joshi and Shine (2003)

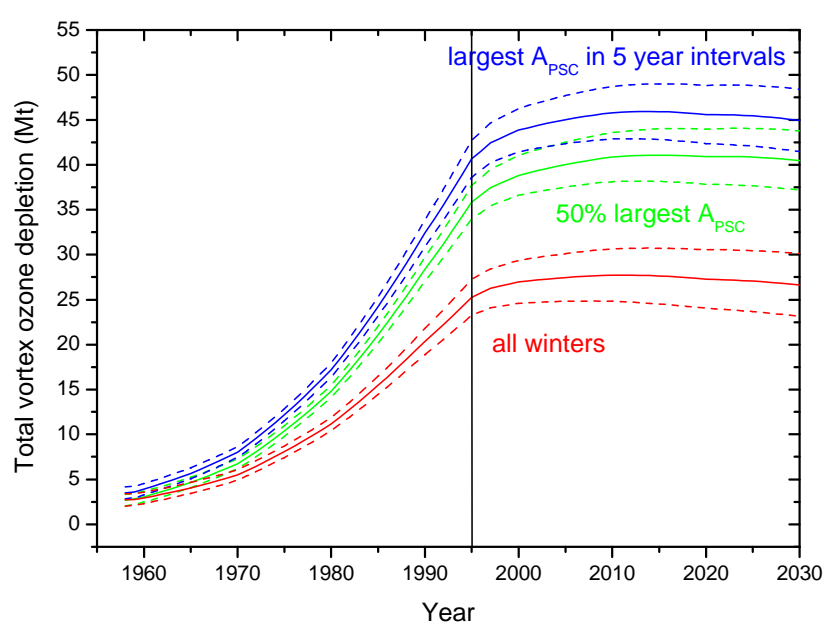

Fig. 4. Future predictions of the ozone depletion using PSC trends for all winters (red), the 50\% largest PSC areas in 6-year intervals (green), and using the largest PSC areas in 5-year intervals (blue). $68 \%$ confidence limits of the PSC extrapolations are shown with the dashed lines.

argue that some the $\mathrm{H}_{2} \mathrm{O}$ trend is due to a trend in volcanic eruptions. About $35 \%$ of the $\mathrm{H}_{2} \mathrm{O}$ trend is due to the trend in methane, which is expected to continue in the future (WMO, 2003). The levelling off of the methane trend in recent years might be due to decreased fossil fuel burning in the former Sovjet Union (Dlugokencky et al., 2003).

Because of the uncertainties about the $\mathrm{H}_{2} \mathrm{O}$ trend (SPARC, 2000) we have studied the sensitivity of the future predictions on the trend. If only the methane related part of the $\mathrm{H}_{2} \mathrm{O}$ trend is taken into account in the calculation of the PSC areas, Fig. 5 shows that less ozone depletion would be expected (green dashed line).

The trends in $\mathrm{H}_{2} \mathrm{O}$, WMGHG, and stratospheric ozone from about 1980-2000 are estimated to have caused a mid December to mid March $50 \mathrm{hPa}$ high-latitude $\mathrm{NH}$ cooling of about 1.1, 0.2, and $0.8 \mathrm{~K}$, respectively (Forster and Shine, 2002; Rosier and Shine, 2000, Schwarzkopf and Ramaswamy, 2002; WMO, 2003). This is quite consistent with the fact that the trend in $\mathrm{T}_{\mathrm{NAT}}$ needed to offset the FU-Berlin $50 \mathrm{hPa}$ PSC trend is $1.0 \mathrm{~K} /$ decade.

Since our results indicate that the future trend of ozone is close to zero, we would expect the temperature trend to decrease. If we assume the PSC trend to be linearly dependent on the modelled depletion we get the following simplistic expression for the PSC areas in the future:

$$
\begin{aligned}
& A_{P S C}(t)= \\
& A_{P S C}(1997)+(t-1997) \frac{A_{P S C}(1997)-A_{P S C}(1979)}{1997-1979} \\
& {\left[1-\frac{C_{\mathrm{O}_{3}}}{C}\left(1-\frac{\Delta \mathrm{O}_{3}(t)-\Delta \mathrm{O}_{3}(1997)}{\left(\Delta \mathrm{O}_{3}(1997) \Delta \mathrm{O}_{3}(1979)\right)(t-1997)}\right)\right]}
\end{aligned}
$$




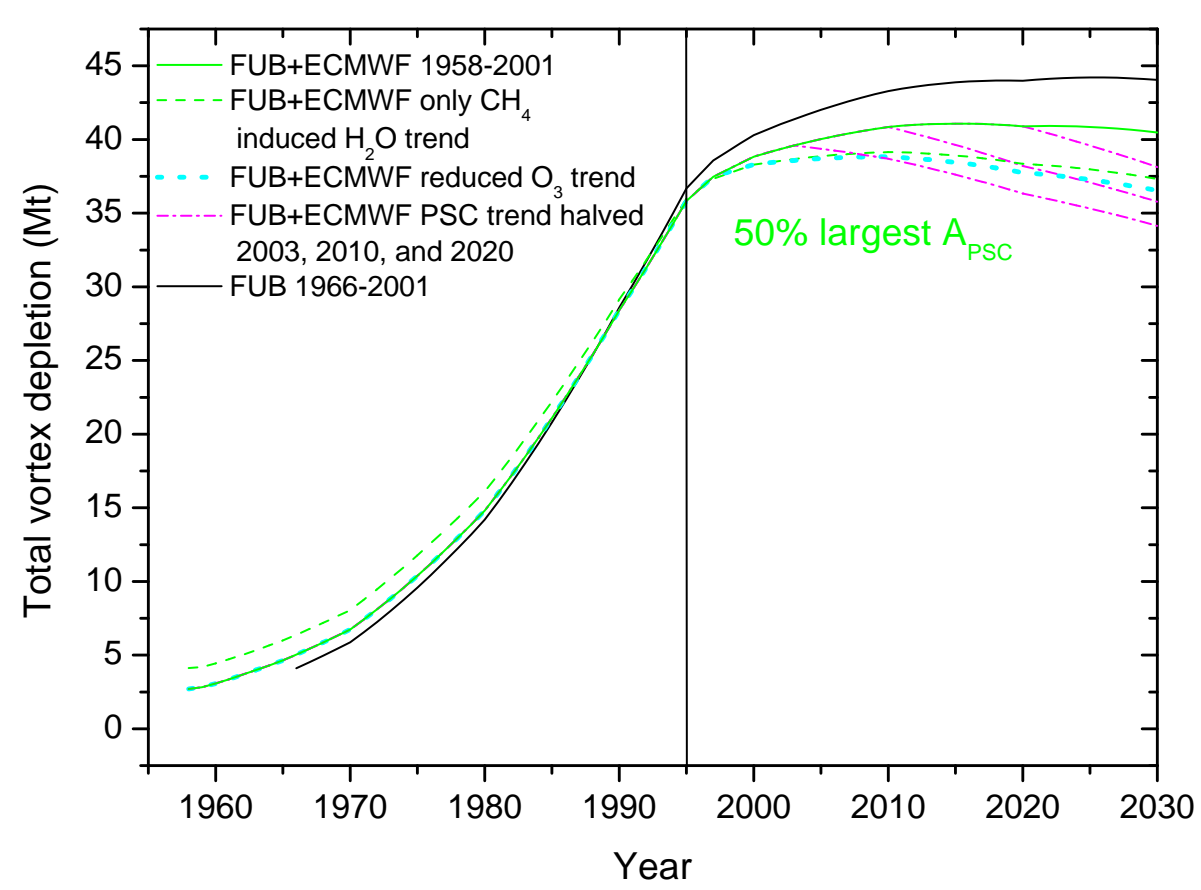

Fig. 5. Sensitivity study of the predicted ozone depletion. The depletions based on the largest 50\% of FUB+ECMWF 1958-2001 PSC areas with a $\mathrm{H}_{2} \mathrm{O}$ trend of 0.05 ppmv/year (green solid line), with only the methane induced trend (green dashed line), and if the PSC trend is halved 2003, 2010, or 2020 (magenta dash-dotted line) are shown. The cyan dotted line shows a tentative estimate of the future ozone depletion if the decreasing ozone trend is taken into account. In black is shown the depletions based on FUB 1966-2001 trends with the 0.05 ppmv/year $\mathrm{H}_{2} \mathrm{O}$ trend.

where $\mathrm{A}_{P S C}(\mathrm{t})$ is the PSC area at time $\mathrm{t}, \mathrm{C}$ is the cooling from 1979-1997 or 1980-2000 $\left(\mathrm{H}_{2} \mathrm{O}\right)$ including the change in $\mathrm{T}_{\mathrm{NAT}}, \mathrm{C}_{O 3}$ is the cooling due to ozone, and $\Delta \mathrm{O}_{3}(\mathrm{t})$ is the ozone depletion at time $\mathrm{t}$.

Since the ozone depletion itself is dependent on the PSC areas in our calculation an iteration was necessary to obtain the future PSC areas. The cyan dotted line in Figure 5 shows that the future ozone depletion in this case maximizes in 2010 at a level 5\% below the pure extrapolation (solid green line) just as for the dashed green line.

If the non-methane related part of the $\mathrm{H}_{2} \mathrm{O}$ trend were to stop the remaining temperature trend would be about half the 1980-2000 trend. Figure 5 shows that halving the PSC trends would lead to a much faster recovery of the ozone layer (magenta dash-dotted line). In the last years $\mathrm{H}_{2} \mathrm{O}$ has decreased (Rosenlof et al., 2003, Randel et al., 2004), but this may be related to changes in the SOI (Scaife et al., 2003). It should be noted that there is no consensus about the attribution of the observed downward trend of the Arctic winter temperatures to the trends in ozone, WMGHG, and water vapour (WMO, 2003). If ozone plays a larger role for the decreasing temperatures the future ozone depletions would become smaller, whereas a smaller role for water vapour would increase the confidence in the future predictions.

Most models used in WMO (2003) predict considerable ozone recovery by 2030 contrary to our results. It is, how- ever, not straightforward to compare our depletions with the minimum column ozone given in WMO (2003). Austin et al. (2003) show that past trends of minimum column ozone are not significantly different from trends in Arctic mean column ozone. Since we predict a colder future, which usually is connected to reduced transport of ozone to the Arctic, including transport is likely to increase the difference in the predicted recovery. However, the difference in the results may partially be able to explain why we do not get as much "ozone depletion" as Shindell et al. (1998). Danilin et al. (1998) also predicted little recovery by 2030 in idealized air parcels using a chemical box model forced by a cooling of $1 \mathrm{~K} / \mathrm{dec}$. Waibel et al. (1999) found ozone recovery to be substantially delayed due to extensive denitrification caused by a cooling of $5 \mathrm{~K}$. Tabazadeh et al. (2000) argue that severe denitrification in the Arctic is possible in the future with a cooling of $4 \mathrm{~K}$ and could enhance ozone loss by up to $30 \%$.

\section{Conclusions}

Using the tight correlation observed between PSC areas and total vortex ozone depletion and taking into account the decreasing amounts of ozone depleting substances, we predict ozone losses in the future. Ozone depletions are predicted to increase until 2010-2015, and decrease slightly afterwards 
as shown in Fig. 4. The confidence limits shown in the figure just give the formal extrapolation errors based on the existing data. They do not include uncertainties in the predicted chlorine loading and the conversion from PSC areas to ozone depletion. Further, predicting the future is always uncertain. Future massive volcanic eruptions would temporarily increase the ozone depletion substantially (Tabazadeh et al., 2002), while a decrease in the $\mathrm{H}_{2} \mathrm{O}$ trend would lead to less ozone depletion as shown in Fig. 5. Despite these uncertainties, we think our empirically based approach is a valuable complementary predictive tool to the chemistry-climate models. However, due to the inadequacies of a simple extrapolation every effort should be undertaken to improve the CCM's.

Acknowledgements. ECMWF is thanked for both the operational and reanalysis data. J. D. Shanklin, British Antarctic Survey, is thanked for the Halley ozone data and J. Pyle and D. Shindell are thanked for valuable comments to the paper. Finally we acknowledge the UARS Reference Atmosphere Project for their climatologies. This study was supported by the EC DG Research through the SCOUT-O3 project (505390-GOCE-CT-2004) and the CRUSOE-II concerted action (EVK2-CT-2001-20012).

Edited by: M. Dameris

\section{References}

Austin, J., Shindell, D., Beagley, S. R., Brühl, C., Dameris, M., Manzini, E., Nagashima, T., Newman, P., Pawson, S., Pitari, G., Rozanov, E., Schnadt, C., and Shepherd, T. G.: Uncertainties and assessments of chemistry-climate models of the stratosphere, Atmos. Chem. Phys., 3, 1-27, 2003,

SRef-ID: 1680-7324/acp/2003-3-1.

Danilin, M. Y., Sza, N.-D., Ko, M. K. W., Rodriguez, J. M., and Tabazadeh, A.: Stratospheric cooling and Arctic ozone recovery, Geophys. Res. Lett., 25, 2141-2144, 1998.

Boer, G. J., Yu, B., Kim, S.-J., and Flato, G. M.: Is there observational support for an El Niño-Like pattern of future global warming?, Geophys. Res. Lett., 31, doi:10.1029/2003GL018722, 2004.

Dlugokencky, E. J., Houweleing, S., Bruhwiler, L., et al.: Atmospheric methane levels off: Temporary pause or a new steadystate?, Geophys. Res. Lett., 30, 19, doi:10.1029/2003GL018126, 2003.

Forster, P. M. de F. and Shine, K. P.: Assessing the climate impact of trends in stratospheric water vapor, Geophys. Res. Lett., 29, 6, doi:10.1029/2001GL013909, 2002.

Gibson, J. K., Kållberg, P., Uppala, S., et al.: ERA description, ECMWF Re-analysis Project Report Series, 1, Reading, United Kingdom, 1997.

Grooß, J.-U. and Müller, R.: The impact of mid-latitude intrusions into the polar vortex on ozone loss estimates, Atmos. Chem. Phys., 3, 403-416, 2003, SRef-ID: 1680-7324/acp/2003-3-403.

Hanson, D. and Mauersberger, K.: Laboratory studies of nitric acid tryhydrate: Implications for the south polar stratosphere, Geophys. Res. Lett., 15, 855-858, 1988.
Joshi, M. M. and Shine, K. P.: A GCM study of volcanic eruptions as a cause of increased water vapor, J. Clim., 16, 3525-3534 ,2003

Knudsen, B. M. and Grooß, J.-U.: Northern mid-latitude stratospheric ozone dilution in spring modeled with simulated mixing, J. Geophys. Res., 105, 6885-6890, 2000.

Knudsen, B. M., Larsen, N., Mikkelsen, I. S., et al.: Ozone depletion in and below the Arctic vortex for 1997, Geophys. Res. Lett., 25, 627-630, 1998.

Knudsen, B. M.: On the accuracy of analysed low temperatures in the stratosphere, Atmos. Chem. Phys., 3, 1759-1768, 2003, SRef-ID: 1680-7324/acp/2003-3-1759.

Knudsen, B. M.: Accuracy of arctic stratospheric temperature analyses and the implications for the prediction of polar stratospheric clouds, Geophys. Res. Lett., 23, 3747-3750, 1996.

Knudsen, B. M. and Andersen, S. B.: Longitudinal variation in springtime ozone trends, Nature, 413, 699-700, 2001.

Labitzke, K., et al.: The Berlin Stratospheric Data Series, CD from the Met. Inst., FU Berlin, 2002.

Lait, L. R., Schoeberl, M. R., Newman, P. A., et al.: Ozone loss from quasi-conservative coordinate mapping during the 19992000 SOLVE/THESEO 2000 campaigns, J. Geophys. Res., 107, doi:10.1029/2001JD000998, 2002.

Oinas, V., Lacis, A. A., Rind, D., Shindell, D., and Hansen, J. E.: Radiative cooling by stratospheric water vapour: Big differences in GCM results, Geophys. Res. Lett., 28, 2791-2794, 2001.

Oltmans, S. J., Vömel, H., Hofmann, D. J., Rosenlof, K. H., and Kley, D.: The increase in stratospheric water vapor from balloonborne, frostpoint hygrometer measurements at Washington, D.C., and Boulder Colorado, Geophys. Res. Lett., 27, 34533456, 2000.

Pawson, S. and Naujokat, B.: Trends in daily wintertime temperatures in the northern stratosphere, Geophys. Res. Lett., 24, 575578, 1997.

Ramaswamy, V., Chanin, M.-L., Angell, J., et al.: Stratospheric temperature trends: observations and model simulations, Rev. Geophys., 39, 71-122, 2001.

Randel, W. J., Wu, F., Oltmans, S., Rosenlof, K. H., and Nedoluha, G. E.: Interannual changes of stratospheric water vapor and correlations with tropical tropopause temperatures, J. Atm. Sci., 61, 2133-2148, 2004.

Rex, M., Salawitch, R. J., von der Gathen, P., Harris, N. R. P., Chipperfield, M. P., and Naujokat, B.: Arctic ozone loss and climate change, Geophys. Res. Lett., 31, L04116, doi:10.1029/2003GL018844, 2004.

Rosenlof, K. H., Oltmans, S. J., Kley, D., et al.: Stratospheric water vapor increases over the past half-century, Geophys. Res. Lett., 28, 1195-1198, 2001.

Rosenlof, K. H., Oltmans, S., and Randel, W.: Recent changes in stratospheric water vapor, paper presented at Eur. Geophys. Soc./Am. Geophys. Union, Nice, 7-11 April, 2003.

Rosier, S. M. and Shine, K. P.: The effect of two decades of ozone change on stratospheric temperatures as indicated by a general circulation model, Geophys. Res. Lett., 27, 2617-2620, 2000.

Scaife, A. A., Butchart, N., Jackson, D. R., and Swinbank, R.: Can changes in ENSO activity help to explain increasing stratospheric water vapor?, Geophys. Res. Lett., 30, 17, doi:10.1029/2003GL017591, 2003. 
Schoeberl, M. R., Newman, P. A., Lait, L. R., et al.: An assessment of the ozone loss during the 1999-2000 SOLVE/THESEO 2000 Arctic campaign, J. Geophys. Res., 107, doi:10.1029/2001JD000412, 2002.

Schwarzkopf, M. D. and Ramaswamy, V.: Effect of changes in wellmixed gases and ozone on stratospheric seasonal temperatures, Geophys. Res. Lett., 29, 24, doi:10.1029/2002GL015759, 2002.

Shindell, D. T., Rind., D., and Lonergan, P.: Increased polar stratospheric ozone ozone losses and delayed eventual recovery owing to increasing greenhouse-gas concentrations, Nature, 392, 589$592,1998$.

Simmons, A. J. and Gibson, J. K.: The ERA-40 project plan, in ERA-40 Project Report Series, No. 1, Available from ECMWF, Shinfield Park, Reading, UK, 2000.

Sinnhuber, B.-M.: Comparison of 3-D model calculations with in situ measurements during SOLVE/THESEO-2000: Implications for our understanding of Arctic ozone loss, proc. 6th Eur. Symp. on Ozone, 426-429, Göteborg, 2-6 September, 2002.

SPARC: SPARC Assessment of Upper Tropospheric and Stratospheric Water Vapour, in Stratospheric Processes and their Role in Climate, WCRP-113, WMO-TD No. 1043, SPARC Report 2, Verrières le Buisson Cedex, 2000.
Tabazadeh, A., Drdla, K., Schoeberl, M. R., Hamill, P., and Toon, O. B.: Arctic "ozone hole" in a cold volcanic stratosphere, Proc. Nat. Acad. Sci. USA, 99, 2609-2612, 2002.

Tabazadeh, A., Santee, M. L., Danilin, M. Y., Pumphrey, H. C., Newman, P. A., Hamill, P. J., and Mergentaler, J. L.: Quantifying denitrification and its effect on ozone recovery, Science, 288, 1407-1411, 2000.

Tolbert, M. A. and Toon, O. B.: Solving the PSC mystery, Science, 292, 61-63, 2001.

von Storch, H. and Zwiers, F. W.: Statistical Analysis in Climate Research, Cambridge University, Cambridge, UK, 484, 1998.

Waibel, A. E., Peter, T., Carslaw, K. S., et al.: Arctic ozone loss due to denitrification, Science, 283, 2064-2069, 1999.

WMO: Scientific Assessment of Ozone Depletion: 1994, World Meteorological Organization Global Ozone Research and Monitoring Project Report No. 37, Geneva, 1995.

WMO: Scientific Assessment of Ozone Depletion: 1998, World Meteorological Organization Global Ozone Research and Monitoring Project Report No. 44, Geneva, 1999.

WMO: Scientific Assessment of ozone depletion: 2002, World Meteorological Organisation Global Ozone Research and Monitoring Project Report No. 47, Geneva, 2003. 